\title{
EDUKASI KESEHATAN TERSTRUKTUR DAN STIGMA MASYARAKAT PADA KLIEN TB PARU
}

\section{STUCTURED HEALTH EDUCATION AND SOCIAL STIGMA IN PULMONARY TB CLIENTS}

\author{
Verra Widhi Astuti ${ }^{1}$, Astuti Yuni Nursasi ${ }^{2 *}$, Sukihananto $^{2}$ \\ ${ }^{1}$ Program Studi Magister Ilmu Keperawatan Universitas Indonesia, Depok, Indonesia \\ ${ }^{2}$ Fakultas Ilmu Keperawatan, Universitas Indonesia, Depok, Indonesia \\ (email penulis korespondensi: ayunin@ui.ac.id)
}

Info Artikel: Diterima: 04 Agustus 2019

Revisi: 20 September 2019

Diterima: 15 Oktober 2019

\begin{abstract}
ABSTRAK
Latar Belakang: Stigma masyarakat merupakan salah satu penghalang keberhasilan pengendalian TB paru. Stigma masyarakat muncul akibat kesalahpahaman masyarakat mengenai TB paru dan penularannya. Hal ini mendorong tenaga kesehatanuntuk mengembangkan intervensi guna menurunkan kesalahpahaman dan pada akhirnya akan menurunkan stigma masyarakat, salah satunya adalah edukasi kesehatan terstruktur. Penelitian ini bertujuan untuk mengetahui pengaruh intervensi edukasi kesehatan terstruktur terhadap stigma masyarakat pada klien TB paru di kabupaten Bogor, Indonesia.

Metode: Desain penelitian kuasi eksperimen jenis pretest and posttest with control group. Penelitian dilakukan 41 responden untuk masing-masing kelompok. Metode pengambilan sampel yaitu purposive sampling untuk memilih wilayah dengan jumlah kasus tertinggi dan responden dipilih dengan simple random sampling.

Hasil: Hasil menunjukkan bahwa edukasi terstruktur secara signifikan menurunkan stigma masyarakat ( $p$ value $=0,0005)$.

Kesimpulan: Edukasi kesehatan terstruktur menurunkan stigma masyarakat. Hasil penelitian diharapkan mampu memberikan alternatif pilihan intervensi keperawatan komunitas yang dapat diberikan kepada masyarakat untuk mengurangi stigma pada klien TB paru..
\end{abstract}

Kata Kunci : edukasi kesehatan terstruktur, stigma masyarakat, TB paru

\section{ABSTRACT}

Background: Public stigma is one of the obstacles to successful pulmonary TB control. Community stigma arises from people's misunderstandings about pulmonary $T B$ and its transmission. This encourages health workers to develop interventions to reduce misunderstandings and ultimately will reduce the public stigma, one of which is structured health education. This study aims to determine the effect of structured health education intervention on public stigma in pulmonary tuberculosis clients in Bogor district, Indonesia.

Methods:this research used quasi-experimental design research with pretest and posttest with control group types. Research conducted 41 respondents for each group. Sampling method is purposive sampling to choose the region with the highest number of cases and respondents selected by simple random sampling. Results: The results show that structured education significantly decrease the public stigma ( $p$ value $=0,0005$ ).

Conclusion: Structured health education decrease the public stigma. The results are expected to provide an alternative choice of community nursing interventions that can be given to the community to reduce stigma in lung TB clients.

Keywords: Structured Health Education, Public Stigma, Pulmonary TB 


\section{PENDAHULUAN}

Stigma merupakan persepsi negatif yang melekat pada seseorang dimana orang tersebut akan terbentuk jarak dengan lingkungan sosialnya dan membawa perasaan malu serta terisolasi. ${ }^{1}$ Stigma masyarakat merupakan reaksi masyarakat umum terhadap kelompok tertentu. ${ }^{2}$ Stigma masyarakat pada TB paru muncul karena masyarakat menduga bahwa TB merupakan penyakit akibat perilaku tidak bermoral, (dianggap) tidak bisa disembuhkan, dan mitos terkait etiologi TB. Stigma masyarakat yang muncul pada penderita TB dalam bentuk penghinaan, ejekan, diskriminasi, pengucilan sosial, dan isolasi sosial. ${ }^{3}$ Hal ini didukung studi lain yang menyebutkan bahwa orang TB mengalami isolasi dari keluarga dam masyarakat, pemisahan, dan krisis ekonomi. ${ }^{4}$

Komunikasi personal dengan masyarakat di Kecamatan Cisarua Bogor menunjukkan bahwa masih terdapat kesalahpahaman mengenai etiologi dan cara penularan TB paru. Mitos terkait etiologi TB paru yang diyakini masyarakat yaitu TB paru merupakan penyakit yang disebabkan karena "gunaguna". Selain itu, terdapat pula kesalahpahaman mengenai cara penularan TB paru yaitu dengan berjabat tangan dan melalui peralatan makan. Komunikasi personal dengann orang yang sakit TB di Kecamatan Cisarua menunjukkan bahwa terdapat stigma masyarakat yang dirasakan seperti menjaga jarak saat orang sakit TB mendekat dan tidak mau untuk duduk berdekatan dengan orang yang sakit TB.

\section{METODE}

Penelitian ini menggunakan desain quasi eksperimen pre dan post tes dengan kontrol grup. Penelitian dilakukan pada bulan Mei 2017 di Kecamatan Cisarua Kabupaten Bogor. Populasi penelitian merupakan masyarakat usia dewasa (2059 tahun) yang tinggal di Kecamatan Cisarua. Penelitian dilakukan di dua desa dengan jumlah kasus TB tinggi yang dipilih melalui purposive sampling, sedangkan responden atau subjek penelitian dipilih menggunakan simple random sampling. Desa Cilember terpilih sebagai kelompok intervensi, sedangkan desa Tugu Utara sebagai kelompok kontrol. Jumlah sampel yang dugunakan dalam penelitian ini yaitu 82 orang usia dewasa, 41
Stigma masyarakat sangat berpengaruh terhadap perilaku seseorang terhadap kesehatan. Stigma yang melekat pada TB dapat berkontribusi pada tertundanya pencarian kesehatan, kepatuhan pengobatan yang rendah, dan prognosis yang buruk. ${ }^{4}$ Studi lain menyebutkan bahwa stigma pada TB mengarah pada penurunan kualitas hidup, status sosial dan kesulitan dalam pemenuhan atau kepatuhan pengobatan. ${ }^{3}$ Dapat disimpulkan bahwa stigma yang diterima oleh penderita TB berhubungan dengan perilaku pencarian kesehatan dan kepatuhan pengobatan yang dapat berdampak pada prognosis yang buruk bagi penderita TB. Untuk itu, perlu dilakukan upaya serius untuk mengurangi stigma masyarakat tentang TB paru.

Penelitian tentang intervensi yang dapat mengurangi stigma di masyarakat belum banyak dilakukan. Namun, pengetahuan yang baik tentang kesehatan dapat meningkatkan pemahaman dan meminimalkan kesalahpahaman. ${ }^{5}$ Artinya edukasi kesehatan secara tidak langsung dapat berpengaruh terhadap stigma masyarakat. Persepsi negatif atau stigma masyarakat dapat diubah melalui edukasi kesehatan dan kontak terhadap masyarakat. ${ }^{6}$ Untuk itu peneliti mengambangkan edukasi kesehatan terstruktur sebagai salah satu intervensi yang diharapkan dapat mengurangi stigma masyarakat pada klien TB paru. Tujuan penelitian ini adalah untuk mengetahui adanya pengaruh intervensi edukasi kesehatan terstruktur terhadap stigma masyarakat.

orang dalam kelompok intervensi dan 41 orang di kelompok kontrol.

Pengumpulan data dilakukan dengan menggunakan kuisioner stigma masyarakat yang dialihbahasakan ke dalam bahasa Indonesia. ${ }^{8}$ Hasil uji validitas dan reliabilitas menunjukkan bahwa kuisioner ini dapat digunakan untuk mengukur stigma masyarakat dengan nilai $r$ tabel $>0,361$ dan alpha Cronbanch 0,870. Edukasi kesehatan terstruktur pada kelompok intervensi dilakukan selama 60 menit. Pada 20 menit pertama diberikan penjelasan melalui ceramah dan dilanjutkan dengan berbagi pengalaman dari penderita TB dan diskusi kelompok. Sedangkan pada kelompok kontrol diberikan edukasi kesehatan tentang gambaran 
umum TB paru selama 20 menit. Hasil penelitian independent t-test. ${ }^{9}$ dianalisis menggunakan analisis pired t-test dan

\section{HASIL}

Tabel 1. Distribusi Karekteristik Responden pada Kelompok Intervensi dan Kelompok Kontrol di Kabupaten Bogor

\begin{tabular}{lcccc}
\hline \multirow{2}{*}{ Variabel } & \multicolumn{2}{c}{ Kelompok Intervensi } & \multicolumn{2}{c}{ Kelompok Kontrol } \\
\cline { 2 - 5 } & Rerata & Standar Deviasi & Rerata & Standar Deviasi \\
\hline Umur & 36,51 & 12,15 & 36,20 & 10,63 \\
\hline Karakteristik & Frekuensi & Persentase & Frekuensi & Persentase \\
\hline Jenis Kelamin & & & & \\
1. Laki-laki & 4 & 9,8 & 5 & 12,2 \\
2. Perempuan & 37 & 90,2 & 36 & 87,8 \\
Suku & & & & 100 \\
Sunda & 41 & 100 & 41 & \\
Tingkat Pendidikan & & & & \\
1. Pendidikan Dasar & 33 & 80,5 & 34 & 14,6 \\
2. Pendidikan & 8 & 19,5 & 6 & 2,4 \\
$\quad$ Menengah & 0 & 0 & 1 & \\
3. Pendidikan Tinggi & & & & 95,1 \\
Status Ekonomi & & & 39 & 4,9 \\
1. $\quad$ UMR & 40 & 97,6 & 2 & \\
2. & 1 & 2,4 & & \\
\hline
\end{tabular}

*Upah Minimum Regional

Karakteristik responden terdiri dari usia, jenis kelamin, suku, tingkat pendidikan, dan status ekonomi. Rata-rata usia responden pada penelitian ini yaitu 36.51 tahun (95\% CI: 32.68-40.35) pada kelompok intervensi dan 36,20 tahun (95\% CI: 32.84-39.55) pada kelompok kontrol, Sebagian besar responden perempuan $(90.2 \%)$, berasal dari suku Sunda (100\%), sebagian besar menyelesaikan pendidikan dasar $(80,5 \%)$, dan sebagian besar memiliki penghasilan di bawah UMR Kabupaten Bogor $(97,6 \%)$.

Hasil analisa bivariat pada variabel stigma masyarakat ditampilkan pada Tabel 2 dan 3 berikut:

Tabel 2. Hasil Analisis Paired T-Test Stigma Masyarakat pada Kelompok Intervensi dan Kontrol di Kabupaten Bogor

\begin{tabular}{|c|c|c|c|c|c|c|}
\hline \multirow{3}{*}{ Variabel } & \multicolumn{6}{|c|}{ Kelompok Intervensi } \\
\hline & \multicolumn{2}{|c|}{ Sebelum } & \multicolumn{2}{|c|}{ Sesudah } & \multirow{2}{*}{$\begin{array}{l}\text { Beda } \\
\text { Mean }\end{array}$} & \multirow{2}{*}{$p$ value } \\
\hline & Rerata & SD & Rerata & SD & & \\
\hline Stigma Masyarakat & 26,90 & 4,33 & 19,93 & 2,31 & 6,97 & 0,000 \\
\hline \multirow{3}{*}{ Variabel } & \multicolumn{6}{|c|}{ Kelompok Kontrol } \\
\hline & \multicolumn{2}{|c|}{ Sebelum } & \multicolumn{2}{|c|}{ Sesudah } & \multirow{2}{*}{$\begin{array}{l}\text { Beda } \\
\text { Mean }\end{array}$} & \multirow{2}{*}{$p$ value } \\
\hline & Rerata & SD & Rerata & SD & & \\
\hline Stigma Masyarakat & 26,98 & 3,89 & 25,78 & 1,2 & 1,2 & 0,001 \\
\hline
\end{tabular}

Hasil analisis Tabel 2 menunjukkan bahwa terdapat penurunan stigma masyarakat yang lebih besar pada kelompok intervensi dibandingkan pada kelompok kontrol. Penurunan stigma pada kelompok intervensi sebesar 6,97 dengan analisis lebih lanjut menggunakan wilcoxon test didapatkan 
$p$ value $=0,000$ yang artinya terdapat penurunan stigma yang signifikan pada kelompok intervensi $(\mathrm{p}<0,05)$. Sedangkan pada kelompok kontrol selisih penurunan stigma sebesar 1,2 dengan $\mathrm{p}=0,001$ yang artinya terdapat penurunan stigma yang signifikan pada kelompok kontrol $(p$ value $<0,05)$.
Dapat disimpulkan bahwa terdapat penurunan secara signifikan rerata stigma masyarakat baik pada kelompok intervensi maupun kelompok kontrol dengan penurunan lebih besar terjadi pada kelompok intervensi.

Tabel 3. Hasil Independen T-Test Stigma Masyarakat pada Kelompok Intervensi dan Kontrol di Kabupaten Bogor $(\mathbf{n}=82)$

\begin{tabular}{clccc}
\hline Variabel & Kelompok & Rerata & SD & p value \\
\hline \multirow{2}{*}{ Stigma Masyarakat } & Intervensi & 19,93 & 2,32 & \multirow{2}{*}{0,0005} \\
& Kontrol & 25,78 & 2,99 & \\
\hline
\end{tabular}

Hasil analisis menunjukkan bahwa rerata stigma masyarakat responden sesudah dilakukan intervensi edukasi kesehatan terstruktur pada kelompok intervensi lebih kecil dibandingkan dengan kelompok kontrol. Hasil uji menunjukkan

\section{PEMBAHASAN}

Rerata stigma masyarakat pada responden baik kelompok intervensi maupun kelompok kontrol sebelum dilakukan intervensi masih tinggi. Hal ini menunjukkan bahwa di daerah penelitian stigma masyarakat pada penyakit TB masih tinggi dengan rerata 26,90 untuk kelompok intervensi dan 26,98 untuk kelompok kontrol. Stigma masyarakat yang tinggi dipengaruhi beberapa hal, salah satunya adalah kondisi pedesaan. Kondisi pedesaan erat kaitannya dengan budaya lokal yang masih kental. Hal ini dapat berpengaruh terhadap cara pandang masyarakat terhadap penyakit TB. bahwa masyarakat perkotaan mempunyai stigma yang lebih rendah dibandingkan dengan pedesaan. ${ }^{10}$

Stigma masyarakat dipengaruhi kondisi sosial ekonomi, dimana masyoritas responden mempunyai penghasilan keluarga dibawah UMR Kabupaten Bogor. Kondisi ekonomi lemah berhubungan dengan ketidakmampuan masyarakat dalam hal pemenuhan kebutuhan nutrisi dan tempat tinggal yang padat serta pemenuhan kebutuhan kesehatan lainnya. ${ }^{11}$ Kondisi sosial ekonomi juga berhubungan dengan persepsi seseorang terhadap penyakit. Kondisi ekonomi lemah berhubungan dengan tingginya stigma masyarakat. ${ }^{10}$

Stigma masyarakat juga dipengaruhi oleh pendidikan seseorang, dimana sebagian besar responden hanya tamat pendidikan dasar. Pendidikan merupakan salah satu cara untuk meningkatkan pengetahuan seseorang. Orang yang bahwa ada perbedaan yang bermakna pada stigma masyarakat sesudah diberi edukasi kesehatan terstruktur antara kelompok intervensi dan kelompok kontrol $(p<0,05)$.

berpendidikan rendah cenderung mempunyai pengetahuan dan kesadaran akan penyakit yang kurang baik, termasuk persepsi negatif terhadap penyakit tertentu seperti TB paru. Orang dengan pendidikan yang rendah mempunyai kemampuan pemahaman yang kurang dibandingkan dengan orang berpendidikan tinggi, hal ini berhubungan juga dengan stigma masyarakat yang tinggi. ${ }^{10}$

Hasil analisis menunjukkan bahwa terdapat perbedaan bermakna rerata skor stigma masyarakat antara kelompok intervensi dan kelompok kontrol terjadi setelah pemberian edukasi kesehatan melalui komunikasi media massa. ${ }^{12}$ Penelitian lain juga melaporkan bahwa terdapat perbedaan bermakna antara kelompok intervensi dan kelompok kontrol setelah diberikan Brief Psychoeducation tentang HIV/AIDS pada ibu rumah tangga. ${ }^{13}$

Perbedaan yang bermakna stigma masyarakat pada kelompok intervensi dan kelompok kontrol terjadi karena ada proses pembelajaran yang dapat meningkatkan pengetahuan masyarakat tentang suatu penyakit. Stigma masyarakat biasanya muncul akibat adanya kesalahan persepsi akibat kurangnya pemahaman terhadap suatu penyakit. Stigma masyarakat pada TB paru muncul karena masyarakat menduga bahwa TB merupakan penyakit akibat perilaku tidak bermoral, (dianggap) tidak bisa disembuhkan, dan mitos-mitos lain terkait etiologi TB. ${ }^{3}$ 
Hasil analisis bivariat menunjukkan adanya perbedaan bermakna rerata skor stigma masyarakat responden setelah diberikan edukasi kesehatan terstruktur pada kelompok intervensi ( $p$ value $=$ $0,000$, alpha $=0,05)$ dan kelompok kontrol $(p$ value $=0,001$, alpha $=0,05)$. Hal ini dapat terjadi karena kedua kelompok sama-sama diberikan edukasi kesehatan. Perubahan rerata skor stigma masyarakat sebelum dan sesudah intervensi juga terjadi setelah pemberian edukasi kesehatan melalui komunikasi media massa ( $p$ value $<0,0001) .{ }^{13}$

Terdapat beberapa metode yang dapat menurunkan stigma, yaitu edukasi, kontak, serta protest dan advocacy. Pada penelitian ini, metode yang digunakan untuk menurunkan stigma adalah metode edukasi yang dilakukan melalui ceramah, berbagi pengalaman (kontak) dan diskusi kelompok. Literature review yang dilakukan beberapa penulis telah menyarankan agar program edukasi kesehatan atau dukungan TB, yang ditujukan untuk penyedia layanan kesehatan, orang dengan TB, dan anggota masyarakat berisiko, dapat mengurangi stigma TB Paru. ${ }^{14}$ Dengan edukasi kesehatan diharapkan pengetahuan akan meningkat sehingga persepsi negatif masyarakat menurun. Hal ini didukung oleh penelitian serupa yang mengemukakan bahwa tingginya stigma pada orang dengan HIV/AIDS berhubungan dengan rendahnya pengetahuan. Dengan demikian, edukasi kesehatan merupakan salah satu cara untuk meningkatkan pengetahuan masyarakat sehingga stigma masyarakat dapat menurun. ${ }^{15}$

\section{KESIMPULAN DAN SARAN}

Edukasi kesehatan terstruktur dapat menurunkan stigma masyarakat pada klien TB paru secara signifikan. Intervensi ini tidak hanya memberikan edukasi kesehatan, tetapi juga diikuti dengan kontak dengan orang yang sudah sembuh dari TB dan diskusi kelompok yang mendorong perubahan persepsi lebih besar dibandingkan hanya

\section{UCAPAN TERIMA KASIH}

Ucapan terima kasih diberikan kepada seluruh pihak yang telah membantu penelitian ini terutama
Kedua kelompok, baik kelompok intervensi maupun kelompok kontrol mempunyai perbedaan yang bermakna stigma masyarakat antara sebelum dan sesudah intervensi. Namun, perbedaan rerata pada kelompok intervensi lebih tinggi dibandingkan dengan kelompok kontrol. Hal ini berkaitan dengan intervensi edukasi kesehatan terstruktur yang diberikan kepada kelompok intervensi, dimana edukasi kesehatan pada kelompok intervensi memberikan intensitas pertemuan yang lebih lama dibandingkan dengan kelompok kontrol. Selain itu, pada kelompok intervensi terdapat kontak dengan orang yang sudah sembuh dari TB untuk berbagi pengalaman. Kontak dapat memberikan dampak lebih besar yaitu diharapkan dua kali lipat dari intervensi edukasi saja. ${ }^{16}$ Stigma dapat diubah melalui peningkatan pengetahuan dengan edukasi kesehatan dan melakukan kontak. $^{6}$

Penurunan stigma masyarakat pada kelompok intervensi yang lebih besar dibandingkan dengan kelompok kontrol juga dapat dipengaruhi oleh media yang digunakan. Pada kelompok intervensi, responden diberikan booklet yang berisi tentang TB paru. Sedangkan pada kelompok kontrol, booklet diberikan setelah dievaluasi. Pesan dalam edukasi kesehatan yang tidak jelas dengan media yang kurang tepat berhubungan dengan adanya stigma dalam masyarakat. ${ }^{4}$ Dengan kata lain peserta edukasi kesehatan dapat membaca booklet yang diberikan untuk mengingat kembali materi yang disampaikan saat sesi edukasi kesehatan agar terhindar dari kesalahpahaman dan dapat menurunkan stigma.

dengan edukasi kesehatan saja. Penelitian selanjutnya dapat dikembangkan dengan menambah metode lain untuk menurunkan seperti protest dan advokasi. Diharapkan intervensi ini dapat diberikan untuk mengurangi stigma masyarakat pada penyakit lainnya seperti kusta.

kepada DRPM sebagai pemberi dana, responden, dan kader kesehatan Kabupaten Bogor. 


\section{DAFTAR PUSTAKA}

1. Goffman. 1963. Stigma: Notes on the management of spoiled identity.Englewood Cliffs, N.J., Prentice-Hall..

2. FiorilloA, Volve U, \& Bhugra D. 2016. Psychiatry in practice: Education, experience, and expertice. United Kongdom: Oxford University Press.

3. Cremers AL, Laat MM. De Kapata N, Gerrets $\mathrm{R}$, Klipstein-grobusch K, \& Grobusch MP. 2015. Assessing the Consequences of Stigma for Tuberculosis Patients in Urban Zambia, Plos One Journal,;113,1-16. http://doi.org/10.1371/journal.pone.0119861

4. Tadesse S. Stigma against Tuberculosis Patients in Addis. Plose One Journal. 2016; 111. http://doi.org/10.1371/journal.pone.0152900

5. Sreeramareddy CT, Kumar HNH, \& Arokiasamy JT. Prevalence of self-reported tuberculosis, knowledge about tuberculosis transmission and its determinants among adults in India: results from a nation-wide crosssectional household survey. BMC Infect Dis, 2013; 1-9. http://doi.org/10.1186/1471-2334$13-16$

6. Stuart GW.Principles and practice of psychiatric nursing. 10th ed. St. Louis: Elsevier. 2014.

7. Yoost B \& Crawford LR. Fundamental of nursing: Active learning for collaborative practice. St. Louis: Elsevier. 2015.

8. Rie A, Van, Sengupta S, Pungrassami P, Balthip Q \& Choonuan S. Measuring stigma associated with tuberculosis and HIV / AIDS in southern Thailand: exploratory and confirmatory factor analyses of two new scales. Tropical Medicine \& International Health, 2008; 13(1), 21-30. http://doi.org/10.1111/j.1365-

3156.2007.01971.x.
9. Dahlan MS.Statistik untuk kedokteran dan kesehatan (edisi ke-4). Jakarta: Salemba Medika. 2010.

10. Jones AR., Cook TM, Wang J. Rural-urban differeces in stigma against agreement with health professionals about treatment. Journal of Affective Disorder, 2011; 134 (1-3):145150. https://doi.org/10.1016/j.jad.2011.05.013

11. Oxlade O\& Murray M. Tuberculosis and Poverty: Why Are the Poor at Greater Risk in India?. Plos One Journal, 2012; 7(11), 18.http://doi.org/10.1371/journal.pone.0047533.

12. Fakolade R, Adebayo S, Anyanti J \& Ankomah A. The Impact Of Exposure To Mass Media Campaigns And Social Support On Levels And Trends Of Hiv-Related Stigma And Discrimination In Nigeria: Tools For Enhancing Effective Hiv Prevention Programmes. Journal of Biosocial Science,2010;42(3), 395-407. doi:10.1017/S0021932009990538

13. Rifai A. Brief Psychoeducation Intervention Against Hiv/Aids Related Stigma Among House Wifes Lived In Coffee Plantation Area. Jurnal KeperawatanMuhammadiyah, 2016; $1(2)$.

14. Courtwright A dan Turner AN. Tuberculosis and stigmatization: Pathways and interventions. Sage Journal, 2010; 125 (4): 3441

15. Feyissa GT, Abebe L, Girma E, \& Woldie M. Stigma and discrimination against people living with HIV by healthcare provider, Southwest Ethiopia. BMC Public Health Journal, 2012; 12: 522. Doi: 10.1186/14712458-12-522.

16. Corrigan PW, Kosyluk KA dan Rusch N.Reducing self stigma by coming out proud. American Journal of Public Health, 2012;103(5), 749-800. 